\title{
Glutathione peroxidase in early and advanced Parkinson's disease
}

\author{
P Johannsen, G Velander, J Mai, E B Thorling, E Dupont
}

\begin{abstract}
A defective antioxidant scavenging system plays a major role in one of the theories of the pathogenesis of Parkinson's disease. The aim of this study was to investigate whether there is a general difference in antioxidant activity between early and advanced cases of Parkinson's disease. Twenty five recently diagnosed patients, without any clinical fluctuations (group $A$ ), and 25 patients in a late phase of the disease with severe fluctuations in response to levodopa therapy (group B) were included in the study. Erythrocyte glutathione peroxidase was determined as a measure of antioxidant activity and significantly lower values were found in group $B$ than in group A. Regression analyses in groups $A$ and $B$ showed significant correlation between glutathione peroxidase and duration of disease, but not between glutathione peroxidase and age of patients.
\end{abstract}

The pathogenesis of the progressive loss of dopaminergic neurons in the substantia nigra (SN), characteristic of Parkinson's disease (PD) has not yet been revealed. One of the theories $^{1-3}$ is that PD patients have a defective antioxidant system, leading to an increased formation of highly reactive free oxygen radicals $\left(\mathrm{O}^{\cdot}\right)$. These are able to react with, for example, poly-unsaturated fatty acids of the cell membranes, thereby causing cells to lyse and die. The free radical formation is a result of monoamineoxidase activity ${ }^{4}$ in the $\mathrm{SN}$, and of the oxidation of dopamine via 6-hydroxy-

Department of Neurology, University Hospital, Aarhus Kommunehospital, Aarhus

P Johannsen

J Mai

E Dupont

Department for Diet and Cancer, Danish Cancer Society, Aarhus

Kommunehospital, Aarhus, Denmark $G$ Velander

E B Thorling

Correspondence to: Dr Johannsen, Neurolab, Department of Neurology, Aarhus Kommunehospital DK-8000 Aarhus C. Denmark

Received 16 January 1990 and in revised form 25 October 1990.

Accepted 15 December 1990 patients was significantly reduced compared with controls. ${ }^{112}$

Studies on erythrocytes (rbc) by Poirrier and Barbeau ${ }^{13}$ did not find any reduction in rbc-GSH, rbc-GSH-px, superoxide dismutase and catalase activity, while a study by Kilinc et al $^{14}$ concluded that the rbc-GSH-px activity was significantly reduced in Parkinsonian patients compared with controls. Thus it is still undecided whether the reduced antioxidant activity found in the SN in PD patients is part of a general aberration or is of local origin.

The main problem in the management of PD is the long-term complications of levodopa treatment, known as the late Parkinsonian syndrome. ${ }^{15} 16$ It consists of highly disabling fluctuations in motor performance and occurrence of abnormal, involuntary movements.

Previous studies on the antioxidant system in PD have not differentiated between early and advanced cases. The possibility that levodopa therapy, via 6-OHDA, might enhance the destruction of the $S N$ (4) makes it relevant to study the possible correlation between the progression of PD and the antioxidant system.

The aim of this study was to determine whether there is a difference in the antioxidant activity, measured by rbc-GSH-px activity and selenium in plasma and erythrocytes, between Parkinsonian patients in the early stages of the disease and patients with advanced disease.

\section{Patients and methods}

Fifty patients with idiopathic PD, selected according to their stage of disease, were included in the study. Forty were outpatients and the rest inpatients admitted for adjustment of anti-Parkinsonian medication and treatment of motor fluctuations at our department between March and July of 1988 . Twenty five were recently diagnosed patients with a smooth response to levodopa (group A), and 25 were in the late stages of the disease with pronounced fluctuations of the therapeutic response (group B). Informed consent was obtained from all patients. The Helsinki II declaration was followed and the study was approved by the local ethical committee.

On the day of examination the patients were rated according to the Unified Parkinson's Disease Rating Scale (UPDRS). ${ }^{17}$ Age and duration of disease for the two groups, as well as their UPDRS-scores, are shown in table 1. tent in the SN in PD patients compared with other parts of the brain. Other studies have shown that the GSH-px activity in SN of PD 
Table 1 Age of patients, duration of disease and UPDRS-score. Results are expressed as mean ( $S D$ ), range in brackets and p-value from Mann-Whitney test between group $A$ and group $B$.

\begin{tabular}{lllll}
\hline & $n$ & Age (years) & $\begin{array}{l}\text { Duration of disease } \\
\text { (years) }\end{array}$ & $\begin{array}{l}\text { UPDRS-score } \\
(0-147)\end{array}$ \\
\hline group A & 25 & $\begin{array}{l}63 \cdot 2(7 \cdot 8) \\
(50-77)\end{array}$ & $\begin{array}{l}3 \cdot 5(1 \cdot 9) \\
(0.5-8)\end{array}$ & $\begin{array}{l}18 \cdot 6(11 \cdot 1) \\
(1-49)\end{array}$ \\
group B & 25 & $\begin{array}{l}68 \cdot 0(5 \cdot 8) \\
(57-78)\end{array}$ & $\begin{array}{l}13 \cdot 2(5 \cdot 1) \\
(4-24)\end{array}$ & $\begin{array}{l}59 \cdot 5(22 \cdot 2) \\
(21-105)\end{array}$ \\
p-value & & $<0.05$ & $<0 \cdot 0001$ & $<0.0001$ \\
\hline
\end{tabular}

The patients were interviewed about their daily food-intake and -habits, and it was noted whether they had taken supplementary vitamins and minerals, especially selenium supplementation. Nine patients in group $A$ and six in group B supplemented with selenium.

A fasting venous blood sample was drawn (40 $\mathrm{ml}$ ). The blood sample was immediately placed on ice and processed at once at the laboratory of the Department for Diet and Cancer, Danish Cancer Society. Erythrocyte glutathione peroxidase (rbc-GSH-px) was measured using the method of Paglia et $a^{18}$ with ter-butylhydroperoxide (from Merck art 820244) as substrate. Plasma- and erythrocyte-selenium were measured according to the method of Watkinson, ${ }^{19}$ as described by Thorling et al. ${ }^{20}$ In group A, one measurement of rbc-selenium from a patient, taking selenium supplementation, was lost during processing.

The statistical analyses were performed by the Statistical Program for Social Science (SPSS-PC). For analyses of significance the Mann-Whitney nonparametric test was used.

\section{Results}

In Table 1 the differences in age of the patients, duration of the disease and the UPDRS-scores are showed.

The rcb-GSH-px level was 30.4 per cent lower in patients of group B (table 2) compared with group $A(p<0.0001) \quad(n=50)$. When excluding those taking supplementary selenium the reduction was 22.4 per cent, but still significant $(p=0.002)(n=35)$. Plasmaselenium was significantly lower in group B than in group $A, 12.5$ per cent $(p=0.03)$ (table

Table 2 Erythrocyte-GSH-px, (mUnits). Results are expressed as mean (SD) and p-value from Mann-Whitney test between group $A$ and group $B$

\begin{tabular}{llll}
\hline & All patients & $\begin{array}{l}\text { Patients without selenium } \\
\text { supplementation }\end{array}$ & $\begin{array}{l}\text { Patients with selenium } \\
\text { supplementation }\end{array}$ \\
\hline group A & $23 \cdot 7(6 \cdot 8)$ & $21 \cdot 4(4 \cdot 7)$ & $27 \cdot 8(8 \cdot 1)$ \\
& $(\mathrm{n}=25)$ & $(\mathrm{n}=16)$ & $(\mathrm{n}=9)$ \\
group B & $16 \cdot 5(3 \cdot 5)$ & $16 \cdot 6(2 \cdot 9)$ & $16 \cdot 1(5 \cdot 4)$ \\
p-value & $(\mathrm{n}=25)$ & $(\mathrm{n}=19)$ & 0.02 \\
\hline
\end{tabular}

Table 3 Plasma-selenium, ( $\mu$ g/l plasma). Results are expressed as mean (SD) and p-value from Mann-Whitney test between group $A$ and group $B$

\begin{tabular}{llll}
\hline & All patients & $\begin{array}{l}\text { Patients without selenium } \\
\text { supplementation }\end{array}$ & $\begin{array}{l}\text { Patients with selenium } \\
\text { supplementation }\end{array}$ \\
\hline group A & $76 \cdot 3(16 \cdot 2)$ & $69 \cdot 8(13 \cdot 4)$ & $87 \cdot 9(14 \cdot 7)$ \\
& $(\mathrm{n}=25)$ & $(\mathrm{n}=16)$ & $(\mathrm{n}=9)$ \\
group B & $66 \cdot 8(12 \cdot 5)$ & $64 \cdot 7(10 \cdot 9)$ & $73 \cdot 7(15 \cdot 7)$ \\
& $(\mathrm{n}=25)$ & $(\mathrm{n}=19)$ & 0.077 \\
p-value & 0.028 & $0 \cdot 25$ & \\
\hline
\end{tabular}

3). When omitting those taking selenium supplementation, however, there was no significant difference between the two groups. Nor did rbc-selenium show any significant differences between the two groups (table 4).

Even though patients from group $B$ took supplementary selenium they did not have an increased rbc-GSH-px level (table 2), or rbcselenium level (table 4). Only plasma-selenium rose by 13.9 per cent (table 3 , fig 1 ), though it is not considered statistically significant. The patients in group A who took supplementary selenium rose significantly both in rbc-GSH-px by 30.1 per cent ( $p=0.015$ ) (table 2 , fig 1 ) and in plasma-selenium by 25.9 per cent ( $p=0.011$ ) (table 3 , fig 1 ), while the 11.2 per cent rise in rbc-selenium in this group from 184 $\mu \mathrm{g} / \mathrm{l}$ cells to $205 \mu \mathrm{g} / \mathrm{l}$ cells (table 4 ) was not significant $(p=0.48)$. The three oldest patients in group $\mathrm{A}$, who took supplementary selenium, showed very high levels in rbc-GSH-px, indicating that the stage of disease may be of more importance than age (fig 2).

As expected a significant correlation between levels of rbc-GSH-px and plasma-selenium was found in group A $(r=0.64$; $\mathrm{p}<0.0005){ }^{21}{ }^{22}$ This did not apply to group $\mathrm{B}$ $(r=0.25 ; p=0.22)$. For the patients without selenium supplementation, no significant correlation between rbc-GSH-px and age was found in either group A or B (fig 1), but a significant correlation between rbc-GSH-px and duration of disease was found within the two individual groups (fig 2).

Erythrocyte-GSH-px shows no significant correlation to the UPDRS-score in group A $(p=0.66)$ or in group $B(p=0 \cdot 20)$.

A significant correlation between plasmaselenium and age was shown in group $A$ in patients without selenium supplementation but not between plasma-selenium and duration of disease (table 5). The opposite was seen in group $B$ in which a significant correlation between plasma-selenium and duration of disease was seen but not between plasmaselenium and age. As shown in table 6 , rbcselenium has no significant correlation with either age or duration of disease in group $\mathbf{A}$, but in group B the results are the same as those for plasma-selenium.

The interview on food habits revealed that there was no difference between the two groups on the estimated energy intake, quality of food or adequacy of nutritional elements that could influence the GSH-px level. The only exception was the selenium supplementation used by 15 of the patients. There was no difference between the sexes concerning any of the parameters.

\section{Discussion}

The aim of this study was to investigate whether there is a difference in antioxidant activity between $P D$ patients at the early stage of their disease and those suffering from advanced PD. We believe that this aim has been fulfilled.

Parkinsonian patients in the late phase of the disease have a lower antioxidant activity as 
Figure 1 Erythrocyte GSH-px plotted against age of patients. $\square$ Group $A$ without selenium, selenium, $n=9$. $\bigcirc$ Group $B$ without selenium, $n=19$. Group $B$ with selenium, $n=6$. Patients without selenium supplementation: Group A: correlation coefficient: $r=-0.3117$ probability: $p=0.24(n=16)$. Group B: correlation coefficient: $r=-0.0721$ probability: $p=0.75$ $(n=19)$. $n=16$. Group $A$ with

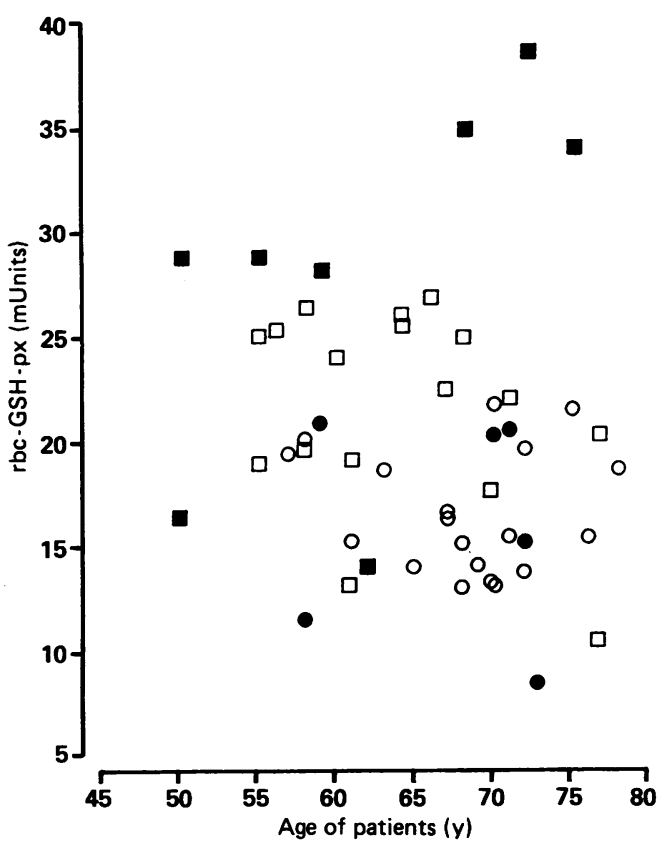

expressed by a significantly decreased rbcGSH-px activity. This decrease could not be explained by differences in dietary habits, energy intake or lack of trace element supplementation. In the single groups $A$ and $B$ rbc-GSH-px does not decrease with age, but the correlation with duration of disease was significant for those patients without selenium supplementation. Those patients who had the longest duration of the disease and advanced symptoms also had the lowest rbc-GSH-px and thus the lowest antioxidant activity. The study cannot tell whether the reduction in rbcGSH-px is a part of the pathogenesis or a result of the disease or the drug treatment. A clue is provided by fig 2 suggesting that the reduction in rbc-GSH-px is a result of the disease or drug treatment due to the steady decline during the years of disease.

Table 4 Erythrocyte-selenium, ( $\mu \mathrm{g} / \mathrm{l}$ cells). Results are expressed as mean (SD) and p-value from Mann-Whitney test between group $A$ and group $B$

\begin{tabular}{llll}
\hline & All patients & $\begin{array}{l}\text { Patients without selenium } \\
\text { supplementation }\end{array}$ & $\begin{array}{l}\text { Patients with selenium } \\
\text { supplementation }\end{array}$ \\
\hline group A & $191(50)$ & $184(45)$ & $205(60)$ \\
& $(\mathrm{n}=24)$ & $(\mathrm{n}=16)$ & $176(41)$ \\
group B & $176(40)$ & $176(40)$ & $(\mathrm{n}=6)$ \\
p-value & $(\mathrm{n}=25)$ & $(\mathrm{n}=19)$ & 0.37 \\
\hline
\end{tabular}

Table 5 Regression analyses of pl-selenium with different variables

\begin{tabular}{lllllll}
\hline & \multicolumn{2}{l}{ Group $A(n=16)$} & & \multicolumn{2}{l}{ Group $B(n=19)$} \\
\cline { 2 - 3 } \cline { 5 - 6 } Plasma-selenium with: & $r$ & $p$ & & $r$ & $p$ \\
\hline Duration of disease & -0.1453 & 0.59 & & -0.5154 & 0.02 \\
Age of patients & -0.6909 & 0.003 & & -0.3014 & 0.21 \\
\hline
\end{tabular}

All patients without selenium supplementation. $r=$ correlation coefficient. $p=$ probability.

Table 6 Regression analyses of rbc-selenium with different variables

\begin{tabular}{llllll}
\hline & \multicolumn{2}{l}{$\operatorname{Group} A(n=16)$} & & \multicolumn{2}{l}{$\operatorname{Group} B(n=19)$} \\
\cline { 2 - 3 } \cline { 5 - 6 } Erythrocyte selenium with: & $r$ & $p$ & & $r$ & $p$ \\
\hline Duration of disease & -0.2278 & 0.40 & & -0.5164 & 0.02 \\
Age of patients & -0.3706 & 0.16 & & -0.3009 & 0.21 \\
\hline
\end{tabular}

All patients without selenium supplementation. $\mathrm{r}=$ correlation coefficient. $\mathrm{p}=$ probability.

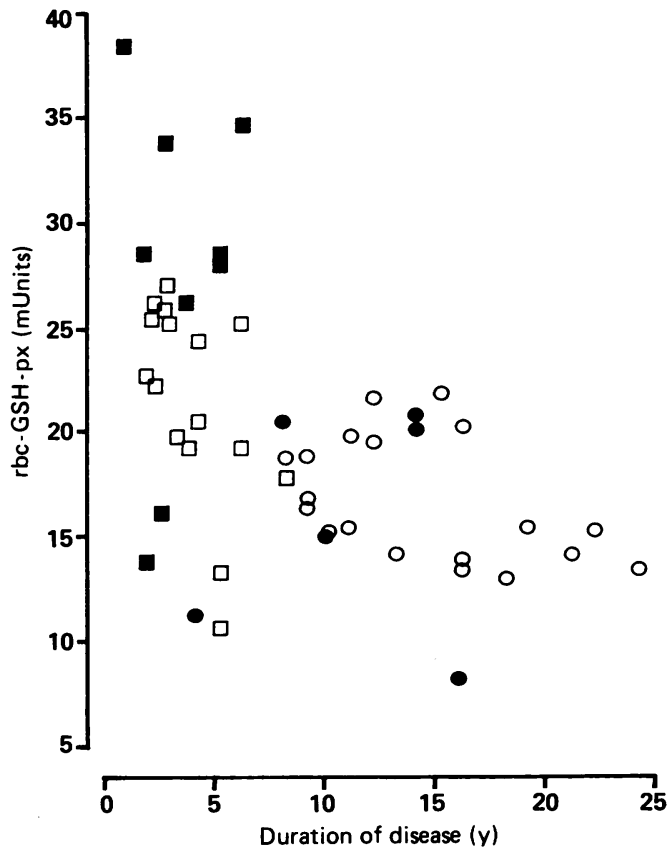

Figure 2 Erythrocyte GSH-px plotted against duration of disease. $\square$ Group $A$ without selenium, $n=16$. Group $A$ with selenium, $n=9$. $\bigcirc$ Group $B$ without selenium, $n=19$. Group $B$ with selenium, $n=6$. Patients without selenium supplementation: Group $A$ : correlation coefficient : $r=-0.5406$ probability: $p=0.03(n=16)$.

Group B: correlation coefficient: $r=-0.4650$ probability: $p=0.04(n=19)$.

So far there has been no consensus on the activity of free radical protecting enzymes in $\mathrm{PD}$. According to Ambani et al ${ }^{11}$ the activity of catalase and peroxidase, the enzymes scavenging hydrogen peroxide, was decreased in SN from PD patients. Perry et al ${ }^{10}$ found virtually absent glutathione, the substrate for GSH-px, in Parkinsonian SN. Also studies by Kish et $a l^{12}$ confirmed a reduced activity of GSH-px in $\mathrm{SN}$ in the brains from $\mathrm{PD}$ patients. However, Poirier and Barbeau ${ }^{13}$ and Marttila et al $^{23}$ did not find alterations in free radical protecting enzymes in peripheral blood from PD patients, indicating no general defect in these enzymes. ${ }^{24}$ This contrasts with results reported by Kilinc et $a l^{14}$ who found decreased GSH-px and glutathione in eythrocytes from PD patients. One explanation as to why no alteration could be detected might be that their studies were based on early PD patients or a mixture of early and late cases, while those who found alterations based their studies on patients in the late phase of Parkinson's disease. Also differences in analytical and sampling procedures may account for some of the differences.

We find the difference between early and late PD patients convincing. We therefore conclude that some general defect in the free radical protecting enzymes does develop over the years of Parkinson's disease. This is supported by the observation that early patients, even those that are elderly, supplementing themselves with selenium, have a high level of rbc-GSH-px, while the late patients, even young ones, seem to have lost the ability to increase their rbc-GSH-px by selenium ingestion and thus have less free 
radical protecting capacity. It is possible that this loss is due to increased oxygen stress induced by the levodopa therapy. This would be in accordance with the impression that combination therapies with dopamine agonists and thereby reduced amounts of levodopa may postpone the development of fluctuations in therapeutic response and of the "on-off syndrome". 25

This study was supported by a grant from "Fonden af 02.07.1984 Til Bekæmpelse af Parkinson's Syge”.

1 Langston JW. Current theories on the cause of Parkinson's. J Neurol Neurosurg Psychiatry. Suppl 1989:13-17.

2 Cadet JL. The potential use of vitamin $\mathrm{E}$ and selenium in parkinsonism. Medical Hypotheses 1986;20:87-94.

3 Barbeau A. Etiology of Parkinson's disease: a research

4 Cohen C. The pathobiology of Parkinsons disease: biochemical aspects of dopamine neuron senescence. J Neurol Transm Suppl 1983;19:89-103.

5 Cohen $G$, Heikkila $R$. The generation of hydrogen peroxide superoxide radical, and hydroxyl radical by 6 -hydroxydopamine, dialuric acid and related cytotoxic agents. $J$ Biol Chem 1974;249:2447-52.

6 Graham DG, Tiffany SM, Bell WR, Gutknecht WF Autooxidation versus covalent binding of quinones as the mechanism of toxicity of dopamine, 6-hydroxydopamine, and related compounds towards $\mathrm{C} 1300$ neuroblastom cells in vitro. Molecular Pharmacology 1978;14:644-53.

7 cells in vitro. Molecular Pharmacology $1978 ; 14: 644$ cells. Biochemical Pharmacology 1985;34:1801-7.

8 Flohe L, Gunzler WA, Schook HH. Glutathione peroxidase: a selenoenzyme. Febs Letters 1973;32:132-4.

9 Carmagnol F, Sinet PM, Jerome H. Selenium-dependen and non-selenium-dependent glutathione peroxidases in human tissue extracts. Biochem Biophys Acta 1983 human tissue

10 Perry TL, Godin DV, Hansen S. Parkinson's disease: A disorder due to nigral glutathione deficiency? Neuroscience Letters 1982;33:305-10.
11 Ambani LM, Van Woert MH, Merphy S. Brain peroxidase and catalase in Parkinson's disease. Arch Neurol 1975;32:114-8.

12 Kish SJ, Morito C, Hornykiewicz D. Glutathione peroxidase activity in Parkinson's disease brain. Neurosci Lett 1985;58:343-6.

13 Poirier J, Barbeau A. Erythrocyte antioxidant activity in human patients with Parkinson's disease. Neurosci Lett 1987;75:345-8.

14 Kilicn A, Yalcin AS, Yalcin D, Taga Y, Emerk K. Increased erythrocyte susceptibility to lipid peroxidation in human

15 Lewitt P, Chase TN. On-off effects the new challenge in parkinsonism. Trends in Neurosciences 1983;6:1-3.

16 Lees AJ. The on-off phenomenon. J Neurol Neurosurg Psychiatry. Suppl 1989:29-37.

17 Fahn S, Elton RL, and members of the UPDRS Development Committee. Unified Parkinson's disease Rating Scale. In: Fahn S, Marsden CD, Calne DB, Goldstein M, eds. Recent developments in Parkinson's disease, vol 2. Florahne Park, NJ: Macmillian Health Care Information, 1987:153-64.

18 Paglia DE, Valentine WN. Studies on the quantitative and qualitative characterization of erythrocyte glutathione qualitative characterization of erythrocyte

19 Watkinson IH. Fluorometric determination of selenium in biological material with 2,3 diamino-naphtalene. Anal Chem 1966;38:92-7.

20 Thorling EB, Overvad K, Heerfordt A, Foldspang A. Serum selenium in Danish blood bank donors. Biol Trace Element Res 1985;8:65-73.

21 Neve J, Vertogen F, Capel P. Selenium supplementation in healthy Belgian adults: response in platelet glutathione peroxidase activity and other blood indices. $\mathrm{Am} \mathrm{J} \mathrm{Clin}$ Nutr 1988;48:139-43.

22 Thomson $C D$, Steven SM, van-Rij AM, Wade $C R$, Robinson MF. Selenium and vitamin E supplementation: activities of glutathione peroxidase in human tissues. $A m J$ Clin Nutr 1988;48:316-23.

23 Martila RJ, Lorentz H, Rinne UK Oxygen toxicity protecting enzymes in Parkinson's disease. Increase of protecting enzymes in Parkinson's disease. Increase of
superoxide dismutase-like activity in the substantia nigra. Neurol Sci 1988;86:321-31.

24 Martila RJ, Rinne UK. Oxygen protecting enzymes in aging and Parkinson's disease. In: Calne DB, et al, eds. Parkinsonism and aging, New York: Raven Press, 1989: $89-95$.

25 Rinne UK. Early dopamine agonist therapy in Parkinson's disease. Movements Disorders (suppl 1), 1989:4:86-94.

\section{Neurological stamp Russia}

\section{Avicenna or Ibn Sina (980-1036 AD)}

He was court physician, vizier to different caliphs and physician in chief to the celebrated hospital in Baghdad, and translator of Galen. Avicenna wrote a gigantic medical tome, and had a great reputation in his time. He gave us the term "vermis" and "tailed nucleus" from which was derived "caudate nucleus".

He described meningitis which he considered to be inflammation or tumour of the envelopes of the brain, and distinguished this from secondary meningism. He knew about the pupil and its movement, of six motor muscles for the globe, and of central and peripheral types of facial weakness. Avicenna defined apoplexy as "loss of sensibility and movement following an occlusion seated within the brain in those places traversed by the nervous influx of sensibility and motricity."

This Russian stamp was issued in 1980 to commemorate one thousand years of his birth. (Stanley Gibbons 5022, Scott 4852).

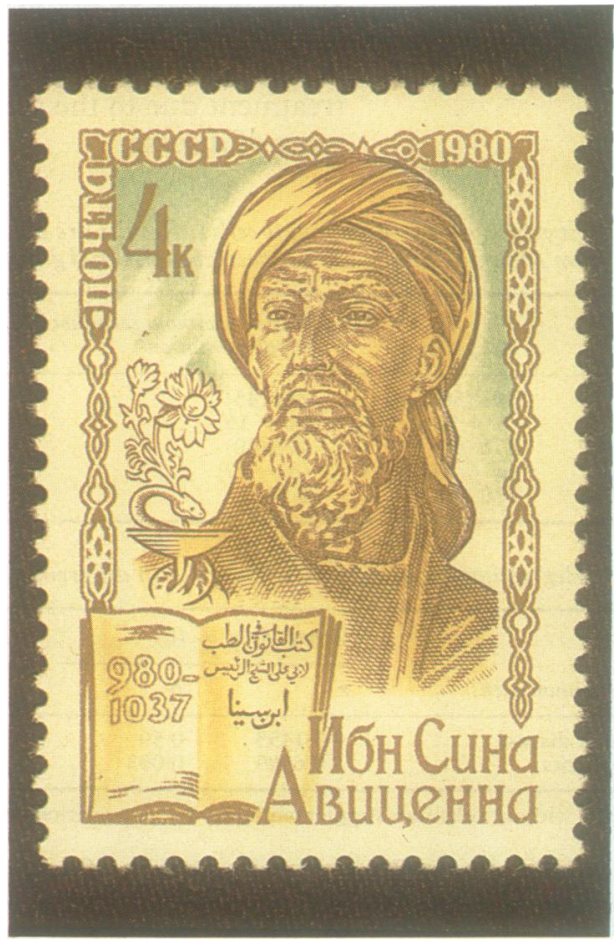

